\title{
Base Nacional Comum Curricular: tensões que atravessam a Educação Básica e a Educação Especial
}

\author{
National Common Curricular Core: \\ tensions through Basic Education and Special Education \\ Base Nacional Común Curricular: \\ tensiones que atravesa la Educación Básica y la Educación Especial
}

\author{
Alexandro Braga Vieira (i) ${ }^{1}$ \\ Sumika SoAREs de Freitas Hernandez-Piloto ${ }^{2}{ }^{2}$ \\ INES DE OLIVEIRA RAMOS ${ }^{1}$ \\ ${ }^{1}$ Universidade Federal do Espírito Santo (UFES), Vitória, ES, Brasil. \\ ${ }^{2}$ Secretaria Municipal de Educação de Vitória, ES, Brasil.
}

\begin{abstract}
RESUMO
Neste artigo discutem-se as tensões produzidas a partir de uma leitura crítica da Base Nacional Comum Curricular. Na primeira parte, problematizam-se ressalvas quanto à composição de currículos mínimos que dificultam que sistemas de ensino, escolas, professores e alunos estabeleçam redes de significação entre os vários conhecimentos existentes, empobrecendo o ato educativo. Além disso, tensionam-se as influências das agências internacionais, nacionais e das avaliações de larga escala que, em nome do ensino de qualidade, promovem processos de exclusão de múltiplos grupos sociais nos currículos escolares. Na segunda parte, relacionamos esse cenário aos pressupostos da educação especial, para promover linhas de análises sobre como propostas curriculares enrijecidas fortalecem a defesa da flexibilização curricular, do aumento de alunos com rótulos de deficiências e da ideia de que é preciso somente pensar nas especificidades de aprendizagem, apartadas do acesso à cultura.
\end{abstract}

Palavras-chave: Currículo. BNCC. Educação Especial.

\begin{abstract}
Discuss tensions produced from a critical reading of the National Curricular Common Base in Brazil. In the first part, reservations about the composition of minimum curricula that make it difficult for education systems, schools, teachers and students to establish networks of meaning between the various existing knowledge, impoverishing the educational act. In addition, the influences of international and national agencies and of large-scale evaluations that, in the name of quality education, promote processes of exclusion of multiple social groups in school curricula are stressed. In the second part, we relate this scenario to the assumptions of special education, to promote lines of analysis about how rigid curricular proposals strengthen the defense of curricular flexibility, the increase of students with labels of deficiencies and the idea that it is necessary Only to think about specificities learning, away from access to culture.
\end{abstract}

Keywords: Curriculum. BNCC. Special Education.

\section{RESUMEN}

Discute tensiones producidas a partir de una lectura crítica de la Basis Nacional Comun Curricular. Primer el texto, problematiza la composición de currículos mínimos que dificultan los sistemas de enseñanza, escuelas, profesores y alunos, una vez que se establece redes de significación entre los vários conocimientos existentes, empobreciendo el acto educativo. Además de eso, se tensiona las influencias de las agencias internacionales, nacionales y de las evaluaciones de larga escala, que en nonbre del enseñanza de calidad promueven procesos de exclusión de múltiples grupos sociales en los currículos escolares. En la segunda parte, relacionamos ese escenário a los presupuestos de la educación especial, para se promover líneas de análisis sobre como propuestas curriculares rígidas fortalecen la defesa de la flexibilización curricular, del aumento de los alumnos con rotulaciones de discapacidad y de la ideia de que es necesario pensar en las especificidades de aprendizaje, apartados del aceso a la cultura.

Palabras clave: Curriculum. BNCC. Educación Especial. 


\section{Currículo Escolar na CONTEMPORANEIDADE}

Ao dialogarmos com Gimeno Sacristán (2000), compreendemos o quanto é complexo produzir uma definição de currículo. Por um lado, algumas linhas de pensamento o significam como um projeto, um plano, uma proposta que define objetivos a serem alcançados, conteúdos a serem ensinados e aprendidos, metodologias a serem empregadas, constituindo o que é denominado por currículo prescrito.

Simultaneamente, há linhas de raciocínio que problematizam uma concepção de currículo como um conjunto de experiências vivenciadas por professores e alunos nas práticas sociais estabelecidas com o conhecimento. Isso diz respeito ao chamado currículo real ou currículo vivido/praticado. Além disso, há constituições teóricas que versam sobre os currículos ocultos, tensionando acerca das normas sociais, princípios e valores que são transmitidos tacitamente por meio do processo de escolarização.

Esses saberes que compõem os currículos ocultos não aparecem explicitamente nos planos educacionais, mas são mediados sistematicamente no dia a dia das salas de aula, por meio das exposições dos professores e dos próprios modos de organização das escolas. Giroux (1986) problematiza que esses valores não são universais, mas, muitas vezes, expressam visões normativas heterogêneas levadas para as escolas sem uma visão crítica. Para o autor, "[...] os valores e crenças do senso comum que guiam e estruturam a prática escolar não são universais a priori, mas construções sociais baseadas em pressuposições normativas políticas" (GIROUX, 1986, p. 70).

Mediante o processo histórico de constituição do currículo e das várias concepções existentes, Gimeno Sacristán (2000) problematiza que ele não é neutro. Ele envolve posicionamentos didáticos, políticos, administrativos e econômicos, pois está imerso em uma realidade amplamente complexa, possuindo interesses de natureza histórica, cultural, política e econômica. Dessa forma, os currículos trazem pressupostos que envolvem culturas, ideologias e relações de poder, produzindo identidades sociais e particulares, permeados por uma visão de mundo que pode reproduzir ou contestar o que é imposto ou ditado pela sociedade contemporânea. Por isso, como problematiza Arroyo (2013), o currículo é um território em disputa.

Como podemos ver, o currículo é a forma como se articula a apropriação/problematização do conhecimento, não podendo esgotar seu significado em algo estático, mas por meio das condições em que se realiza e se converte em uma forma particular de entrar em contato com as culturas. Os debates no campo do currículo se dão por meio de muitos enfrentamentos, pois há de se pensar que vivemos em uma sociedade plural constituída por várias culturas que precisam ser retratadas nos currículos escolares.

Mesmo mediante o avanço na compreensão da pluralidade cultural brasileira e da realização de estudos que demonstram que os currículos escolares historicamente deram supremacia a determinados aspectos da cultura - enquanto negaram muitos outros - (APPLE, 2006; MOREIRA; SILVA, 2008), desde os anos 1980 (ou antes disso), no Brasil, é feita a defesa pela constituição de uma base nacional comum curricular (MACEDO, 2014). Tal situação pode ser percebida na Lei de Diretrizes e Bases da Educação Nacional, no 9.394/96, quando é determinado que o currículo terá $60 \%$ de conteúdos comuns para a Educação Básica e os demais $40 \%$ serão trabalhados de acordo com os aspectos culturais de cada região do País. Posteriormente, outros documentos, como Parâmetros Curriculares Nacionais, o Referencial Curricular Nacional para a Educação Infantil, as Orientações Curriculares para o Ensino Médio, vêm dando continuidade à defesa de uma base curricular comum, situação que aguça os debates no campo do currículo.

Como acompanhamos nos últimos anos, a elaboração de uma base nacional comum curricular voltou a constituir foco de análise no meio acadêmico, político e educacional. Esse debate se fortaleceu com a elaboração do Plano Nacional de Educação (2014-2024), que culminou na constituição da Base Nacional Comum Curricular (BNCC), pelo Ministério da Educação, levando vários pesquisadores, professores e gestores educacionais a refletirem sobre as concepções e encaminhamentos trazidos pelo documento sobre os modos de se trabalhar o conhecimento na escola.

Com a aprovação do Plano Nacional de Educação (Lei n. 13.005/2014), intensificaram-se os debates sobre a elaboração de uma Base Nacional Comum Curricular. Uma primeira tentativa foi com a constituição do documento: "Por uma política curricular para a educação básica: contribuição ao debate da Base Nacional Comum a partir do direito à aprendizagem e ao desenvolvimento". Já a segunda, a Base Nacional Comum Curricular (BNCC) que, depois de várias versões, foi aprovada em 2017.

Vários pesquisadores (ALVES, 2014; MACEDO, 2014) sinalizam preocupações sobre a formulação de uma base nacional comum curricular, estando, dentre elas, a interferência de agências internacionais (como o Banco Mundial) e de conglomerados financeiros constituídos por empresas privadas que buscam interferir nas políticas públicas por meio de ideologias hegemônicas que ditam concepções de sociedade interferindo no que se define como conhecimento válido, no modo de se subjetivar as organizações familiares, nas concepções de gênero, nas 
orientações sexuais e religiosas, dentre outras, mantendo perspectivas de maior controle sobre os currículos escolares.

Além disso, surgem reflexões acerca da composição de um currículo único e mínimo em detrimento a uma diversidade cultural rica que é a realidade brasileira, abdicando, assim, de um conhecimento criativo, pautado na autonomia escolar. Com isso, surgem preocupações sobre a constituição de um ensino pasteurizado, conteudista, antiplural e antidemocrático na medida em que se retira a autonomia dos sistemas de ensino, das escolas e dos profissionais da Educação, principalmente quando negam uma ecologia de saberes e promovem o epistemicídio de muitos conhecimentos (SANTOS, 2006) quando metas/ objetivos são traçados para serem apresentados no final de um ano letivo, levando as escolas a apresentarem resultados (mesmo que de forma camuflada), sejam eles expressos em avaliações locais e/ou nacionais.

Outra preocupação apontada na elaboração da Base Nacional Comum Curricular se pauta na defesa de uma Educação a partir de um padrão de qualidade. Diante disso, há dúvidas quanto ao teor da expressão "padrão de qualidade" e para quem ela se endereça. Muitas vezes, traça-se um padrão de qualidade para um padrão de aluno e a coloca como mais relevante que o estudante concreto que está na escola. Atende-se às agências internacionais por meio de conteúdos e testes padronizados em nome de um ensino de qualidade para todos. Diante disso, não se questiona: qual a trajetória escolar dos alunos? Como eles chegaram às escolas? Quais as suas condições concretas de vida? O que eles alcançaram? O que avançaram? Quais os processos? Como eles se relacionam com o conhecimento? Como aprendem?

Meirieu (2002) acena para a necessidade de vivermos momentos pedagógicos, ou seja, experiências exitosas de ensino-aprendizagem com alunos concretos. Para tanto, é preciso que o professor reflita: qual a trajetória escolar e de vida dos alunos? O que eles sabem? O que eles não sabem? Como aprendem? Como significam? Que linhas de raciocínio promovem? Que apoios necessitam? Que intervenções diferenciadas precisam? Como reorganizar os tempos escolares com os tempos de aprendizagem? Como criar contextos para os alunos estabelecerem suas relações com os conhecimentos?

Esse cenário se aproxima dos estudos de muitos pesquisadores (CARVALHO; 2011; FERRAÇO, 2011) do campo do currículo quando defendem a importância de as escolas se pautarem em perspectivas curriculares que estimulem e valorizem a diversidade e a diferença existentes em sala de aula. Para esses autores é preciso valorizar o pensar e as redes que os alunos e os professores estabelecem com os conhecimentos que tecem nas relações sociais dentro e fora das escolas.
Muitos desses profissionais, alimentados pelas ideias de Boaventura de Sousa Santos (2006; 2008), defendem que cabem às escolas proporcionar aos estudantes o interesse pela pesquisa para que façam a tradução dos vários conhecimentos existentes na vida social, rompendo, assim, com a transmissão enciclopédica de conteúdos.

O currículo, nessa dimensão, proporciona o acesso a um conhecimento prudente, que leva à reflexão crítica de uma vida decente (SANTOS, 2008), por isso, não pode ser subjetivado como um cardápio de conteúdos, mas uma conversa complicada que cada sujeito faz consigo e com o mundo (MACEDO, 2014), ou seja, por meio do acesso ao conhecimento, o estudante tem o direito de analisar criticamente os modos pelos quais a sociedade se organiza, opera os processos de desigualdade/exclusão e nela se desenham os movimentos de resistência a esses processos. Nesse cenário, esse sujeito tem o direito de ver como se encontra posicionado e de analisar o papel da Educação na transformação da sociedade e da sua vida em particular.

Outra preocupação apontada na elaboração da Base Nacional Comum Curricular é a relação estabelecida com as avaliações de larga escala quando determinados "conhecimentos legitimados" são explorados em sala de aula, desconsiderando muitos outros e, muitas vezes, não estabelecendo um diálogo/relação com a vida social do estudante. $\mathrm{O}$ conhecimento serve à escola e às avaliações escolares e de larga escala, mas não à formação integral do sujeito. Além disso, esse processo promove um rankeamento das escolas, fazendo-as competirem entre si, pois precisam evidenciar quem tem a melhor nota, mesmo que promovam processos de exclusão de muitos estudantes ou neguem a entrada daqueles considerados "impróprios" (por exemplo, os com deficiência) por receio de eles rebaixarem os índices da unidade de ensino.

Mediante as preocupações quanto aos rumos que podem trazer uma Base Nacional Comum Curricular construída em um cenário permeado pela evocação de pressupostos antidemocráticos e fundamentalistas, a Associação Nacional de Pós-Graduação e Pesquisa em Educação (ANPED) apresentou ao Ministério da Educação um manifesto contendo o posicionamento de vários pesquisadores brasileiros sobre alguns princípios trazidos no documento em tela, evidenciando o quanto o currículo é permeado por ideologias, culturas e relações de poder (MOREIRA; SILVA, 2008).

Nesse sentido, e indo além, é importante assinalar que, em tempos de ruptura e questionamento dos campos disciplinares em todo o mundo, a construção de uma Base Nacional Comum Curricular a partir, e somente orientada por conteúdos definidos por especialistas em diferentes áreas do conhecimento é uma proposta natimorta. Tal proposta desconsidera relações inter 
e entre as áreas e os conhecimentos que lhes seriam próprios e constitutivos, além de não ser capaz de contemplar algumas das metas especificadas nos protocolos propostos, a de "atribuir conteúdo social" aos conteúdos escolares, visto serem esses respostas a relações e sentidos que transcendem os próprios conteúdos (ASSOCIAÇÃO NACIONAL DE PÓSGRADUAÇÃO E PESQUISA EM EDUCAÇÃO, 9 de novembro de 2015).

Arroyo (2000) problematiza que é tarefa do Estado elaborar orientações básicas para o currículo e para a Educação Nacional. No entanto, algumas premissas não podem passar despercebidas. Uma proposição curricular não pode estar desatrelada de um projeto de sociedade que se pretende construir, portanto, não podemos pensar em um único aspecto da cultura, mas nos vários embates políticos, econômicos e culturais presentes na sociedade contemporânea que precisam compor os currículos escolares. Além disso, é necessário incorporar à base comum as experiências exitosas das escolas, estabelecidas nas relações que professores e alunos constituem com o conhecimento. Somado ao exposto, é fundamental o exercício da democracia na elaboração de uma base curricular nacional, promovendo um cenário dialógico para que universidades, professores, alunos, sociedade civil, pais, movimentos sociais, gestores, dentre outros, possam discutir criticamente a elaboração de um documento que realmente retrate a Educação como um direito público e subjetivo e a diversidade/diferença que compõem a realidade social, cultural, política e econômica do Brasil.

\section{Currículo e EducaÇÃo Especial}

A Educação inclusiva é um panorama filosófico, político e pedagógico que visa acolher, nas classes regulares, diferentes sujeitos, garantindo-lhes os direitos de aprender e de atingir níveis elevados de ensino (BRASIL, 2008; MENDES, 2006). Em processo de solidificação no Brasil, desde os finais dos anos de 1980, a educação inclusiva vem se compondo como consequência de lutas firmadas pelos inúmeros movimentos sociais para que sujeitos historicamente afastados nos bancos escolares venham ter o direito de estudar, de pesquisar e de divulgar o pensamento, conforme prescreve a Constituição Federal do Brasil de 1988.

Dentre os grupos sociais que passaram a compor os cenários educacionais, a partir dos pressupostos da Educação inclusiva, temos os estudantes com deficiência, transtornos globais do desenvolvimento e altas habilidades/superdotação que repercutem um grupo social historicamente não abarcado pelas políticas educacionais e isolado do convívio social. Em virtude do afastamento do Estado acerca da escolarização desses sujeitos, esse processo foi sendo negligenciando, ocorrendo por meio de intervenções de caráter clínico-terapêutico em instituições especializadas, sem relações com os currículos escolares.

Com o processo de redemocratização do País, a Educação Especial passa a ser assumida como modalidade de ensino, ou seja, como transversal e não substitutiva à escolarização dos alunos, sendo referendada como modalidade na Constituição Federal de 1988, no Estatuto da Criança e do Adolescente (Lei no 8.069/90), na Lei de Diretrizes e Bases da Educação Nacional (Lei no 9.394/96) e no Plano Nacional de Educação (Lei $\mathrm{n}$ - 13.005/2014), assim como em outras normativas nacionais e incumbências internacionais.

Diante disso, o processo de escolarização de alunos com indicativos à Educação Especial se fundamenta no pressuposto da Educação como direito público e subjetivo (de todos e dever do Estado) com a garantia da oferta do atendimento educacional especializado como suplementar/complementar (e não substitutivo aos currículos escolares) para atendimento às especificidades de aprendizagens dos estudantes. Cury (2002) afirma que no Brasil, a Constituinte de 1988 é um marco quando reconhece o direito à Educação como público subjetivo.

O direito público subjetivo é um dos mais fortes da lei em termos de proteção e garantia de uma prerrogativa fundamental, pois “"[...] direito público subjetivo está amparado tanto pelo princípio que ele o é, assim por seu caráter de base e por sua orientação finalística, quanto por uma sanção explícita quando de sua negação para o indivíduo cidadão" (CURY, 2002, p. 7).

Os movimentos sociais constituídos em favor da matrícula de alunos com deficiência, transtornos globais do desenvolvimento e altas habilidades/superdotação nas escolas comuns vêm trazendo essa temática para os debates feitos no campo do currículo, tendo em vista a luta pela ampliação da compreensão dos processos de inclusão perpassando pelo acesso, permanência e apropriação do conhecimento. A Política Nacional de Educação Especial na Perspectiva da Educação Inclusiva (BRASIL, 2008) afirma que houve um salto, entre 1996 a 2006, de 640\% das matrículas nas escolas comuns de alunos apoiados pela Educação Especial, situação que evidencia avanços na luta em favor da escolarização desses sujeitos, mas também desafios para as práticas pedagógicas e para a formação dos professores que se perguntam o que ensinar a esses alunos, reforçando a necessidade de debates profícuos sobre a composição de currículos mais acessíveis e abertos.

Quando refletimos sobre a relação entre currículo e Educação Especial tensões atravessam o processo. Um primeiro ponto de análise se relaciona com aspectos apresentados na primeira parte deste texto. Temos 
alunos com especificidades, com trajetórias de vida e com processos de escolarização negligenciados ou não considerados por uma Base Nacional Comum Curricular que prima por um ensino pasteurizado, conteudista, antiplural e antidemocrático. Diante de um currículo prescrito e inacessível, a escola se vê diante de muitos dilemas e perguntas: esse sujeito aprende? O que ele aprende? O que ensinar? O que ele aprendeu tem valor? Ele passa ou não passa ao final do ano letivo? Parece que o professor, diante desse cenário, desenvolve certa paralisia docente (VIEIRA, 2015), pois se depara com um aluno que não se encaixa em um currículo que vem pronto e que em nada cede para validar o que o aluno pode e aprendeu na escola.

Outra tensão é a ideia de padrão de qualidade que também é pensada a partir de um padrão de aluno. Muitos conhecimentos selecionados são apresentados aos estudantes, mas que não retratam a realidade social desses sujeitos. Além disso, não respeitam suas trajetórias de vida, suas aprendizagens, seus modos de significação, seus tempos, suas linhas de raciocínio e as relações que estabelecem com o conhecimento. Os efeitos dessas escolhas resultam na promoção da ideia de que os alunos atuais não têm condições de aprender. Os professores afirmam: "Eles não querem aprender". "Eles não aprendem". "Já fiz de tudo, mas ele não consegue". Já nos anos iniciais do Ensino Fundamental, há a naturalização do fracasso escolar e porque não dizer na Educação Infantil.

Com isso, crescem vertiginosamente os índices/números de crianças com suspeitas de deficiências/síndromes ou "crianças que precisam de laudos", como assim sinalizam os docentes. Se, em tempos remotos existiram crianças chamadas de "levadas", "arteiras", "bagunceiras" (não defendemos aqui rótulos), mas mesmo com esses "rótulos" pareciam crianças, atualmente, todas elas parecem que perderam suas identidades infantis em nome das rotulações clínicas que as denominam como hiperativas, com déficit de concentração, com autismo, com psicose e recentemente com TOD (Transtorno Opositor Desafiador). Com os olhos da clínica, emitem-se laudos subjetivos (VIEIRA, 2015) que são diagnósticos produzidos na cotidianidade das escolas mediante currículos inacessíveis e práticas pedagógicas que apresentam os conhecimentos de maneira pouco atrativa produzindo uma imensidade de estudantes não propensos a aprendizagens e que fazem aumentar as filas em busca dos tão procurados "laudos médicos". Isso porque paira a ideia que de a pessoa com deficiência/sindrômica não aprende e o laudo é o termômetro que irá validar a não aprendizagem.

Esse cenário é referendado pela ideia de que os professores já têm dificuldades em ensinar os ditos normais (para os quais não podem negar que "tiveram" formação), portanto não lhes resta tempo e condições de se envolverem com aqueles que possuem algum tipo de deficiência ou para aqueles que trazem possíveis suspeitas para as escolas. A esses lhes resta à convivência com estagiários, que acabam por assumir a docência, quando deveriam aprofundar seus saberes sobre como ser professor, situação a ser assumida pelos mediadores do conhecimento no espaço-tempo da sala de aula, contando com os apoios necessários que essa ação necessita, sempre que necessário, e as devidas condições de trabalho e de formação.

Quando esse cenário é atravessado pelas avaliações de larga escala ou por cobranças dos sistemas de ensino que determinam as metas a serem alcançadas, sem mesmo realizar diagnósticos das escolas e das turmas para compor um plano de ação para que todos os alunos tenham condições de aprender e os professores possibilidades de ensinar, os desafios se tornam amplamente plurais. Por isso, cabe pensar: qual a concepção de sujeito de direito que a Base Nacional Comum Curricular defende? Como os pressupostos da Educação Especial transversalizam o documento? Quais os espaços para se tratar a diversidade/ diferença humana? Como aponta pistas para se articular o currículo comum ao atendimento educacional especializado? Geralmente, pensa-se em um documento curricular para um padrão de aluno e compõem-se anexos/apêndices para se tratar das especificidades de determinados grupos sociais como se eles vivessem de especificidades e não tivessem o direito de acessar determinados referenciais culturais comuns e necessários ao processo de humanização.

É por meio da composição de documentos orientadores feitos a partir de sujeitos padronizados que nascem conceitos como adaptações, flexibilizações e adequações curriculares. Como o currículo está pronto, paira a ideia de que ele precisa ser adaptado para os estudantes que possuem deficiência, transtornos globais do desenvolvimento e altas habilidades/superdotação, mesmo que a literatura produzida no campo da Educação Especial (HASS; BAPTISTA, 2015; CORREIA, 2016), aponte preocupações acerca do uso recorrente desses conceitos, acenando o quanto (por meio deles) se têm constituído currículos mínimos, enxutos e pobres, por sua vez pensados para as deficiências dos alunos e não para sujeitos históricos e sociais.

Quando as exigências curriculares não são cumpridas por todos da mesma forma, inevitavelmente surgem as diferenças entre os estudantes. As 'pequenas distâncias' em relação ao ideal geralmente assumidas como naturais. Um grande distanciamento será qualificado como fracasso e poderá ser motivo de repetência da série. Quando o fracasso persiste, a 'singularidade' individual está destinada ao abandono (GIMENO SACRISTÁN, 2002, p. 20). 
Diante disso, Correia (2016) defende que há de se constituir um olhar crítico sobre a deficiência e sobre os currículos escolares para pensarmos a Educação Especial na lógica do direito à Educação. A autora sinaliza que o tamanho da deficiência do sujeito é proporcional às barreiras impostas pela sociedade. Com isso, rompe com uma concepção biológica de deficiência e se aproxima de uma perspectiva social/cultural. No campo do currículo, argumenta que em tempos de flexibilização, adaptação e adequação curricular é preciso se aproximar da ideia de acessibilidade ao currículo, ou seja, da criação de contextos de ensino-aprendizagem para que os alunos tenham acesso a um conhecimento que os toque e que promova o vínculo social entre o sujeito e a sociedade (MEIRIEU, 2002). Com isso, convoca os professores a refletirem sobre o planejamento e a mediação de práticas pedagógicas que acompanhem as trajetórias dos alunos, oferecendo-lhes os apoios e os recursos necessários para acessar os conhecimentos mediados na coletividade da sala de aula comum em uma relação profícua com o AEE.

Por isso, é preciso pensar a relação entre currículo e Educação Especial para além do conceito de flexibilização curricular, ainda muito marcada no campo da Educação Especial. Para tanto, faz-se necessário acompanhar o andamento de políticas que favorecem a articulação entre a sala regular comum e o atendimento educacional especializado para a criação das condições necessárias para que os alunos tenham ampliadas suas possibilidades de acessar os conhecimentos na coletividade da sala de aula comum com os apoios trazidos pelo AEE, por sua vez expostos de maneira ampla na escola e não restritos em salas de recursos multifuncionais.

Em assim sendo, concordamos com Baptista (2011, p.11), quando defende que a "[...] prática do educador especializado não deve se restringir a um espaço físico e não seja centralizado em um sujeito a ser 'corrigido', mas uma ação plural em suas possibilidades e suas metas". Isto posto, o atendimento educacional especializado deve se colocar a serviço das ações planejadas e desenvolvidas pela sala de aula comum, tendo como horizonte a ampliação do acesso ao currículo escolar pelo estudante apoiado pela Educação Especial.

Garcia (2007) e Prieto (2009) destacam que, na década de 1990, com os investimentos de novas diretrizes curriculares para a área da Educação, cresceram as reflexões sobre as adaptações curriculares. A primeira autora problematiza o quanto o debate se dava em torno das capacidades individuais do sujeito e da necessidade de se dar respostas a cada tipo de interesse e habilidade, por meio de adaptações de métodos, técnicas, recursos, dentre outros elementos, no entanto, sem um debate mais profícuo com a aprendizagem humana que se dá por meio da relação com o outro. Prieto (2009), em sua análise, considera que as adequações curriculares estiverem configuradas nos alunos com deficiências, altas habilidades e superdotação e transtornos globais do desenvolvimento como se somente eles tivessem condições diferenciadas de aprendizagem, negligenciando, assim, um dos princípios centrais da inclusão: o reconhecimento da heterogeneidade.

Dando continuidade às problematizações que atravessam a relação entre os currículos escolares e a Educação Especial, encontramos certa centralidade nos debates e nos estudos em especificidades constitutivas da modalidade. Atualmente, avolumam-se produções sobre o atendimento educacional especializado e um envolvimento ainda tímido nos debates firmados no campo do currículo propriamente dito. A Base Nacional Comum Curricular organiza orientações em torno de áreas do conhecimento - Linguagens, Matemática, Ciências da Natureza, Ciências Humanas e Ensino Religioso - perpassando por toda a Educação Básica, no entanto sem considerar a existência de sujeitos com deficiência, transtornos globais do desenvolvimento e altas habilidades/superdotação, ou seja, sem transversarlizar encaminhamentos quanto aos direitos de envolvimento desses sujeitos em cada uma dessas áreas de conhecimento. Há de se lançar uma escuta sensível (BARBIER, 2004) para as especificidades da modalidade, mas também, para questões gerais da Educação (relacionando-as à Educação Especial) pelo fato de ambas implicarem os processos de escolarização dos alunos.

Se, considerarmos que a Política Nacional de Educação Especial na Perspectiva da Educação Inclusiva de 2008 e documentos posteriores promulgados (Resolução n. 4/2009 e Decreto n. 7.611/2011) consideram que o atendimento educacional especializado se coloca como complementar/suplementar aos currículos escolares e nunca substitutivos à escolarização dos alunos, é preciso somar esforços em favor da composição de documentos orientadores que reconheçam o direito a conhecimentos basilares à formação humana, resguardando às especificidades que atravessam cada grupo social.

Meirieu (1997) nos ajuda a pensar que na elaboração de documentos que orientam o trabalho com o conhecimento dentro de uma determinada realidade social, há de conjugar esforços para se fazer dialogar os pressupostos da igualdade e da diferença para que as pessoas se sintam suficientemente semelhantes para poderem falar umas com as outras e suficientemente diferentes para terem qualquer coisa a dizerem umas às outras. Já no dizer de Boaventura de Sousa Santos (2006), trata-se do direito que cada ser humano tem de se sentir igual quando a diferença busca inferiorizá-lo, bem como o direito de ser diferente quando a igualdade tenta descaracterizá-lo. 
Diante disso, é tão importante pensar nos modos como organizar as salas de recursos multifuncionais, nas ações nelas realizadas, nos tempos de atendimento aos alunos no AEE, nas especificidades de aprendizagens dos alunos, na formação dos professores especializados, mas também em como os documentos norteadores dos currículos escolares contemplam (ou não) os alunos atendidos pela modalidade de Educação Especial, a formação dos professores do núcleo comum, as práticas pedagógicas desenvolvidas na sala de aula regular, os modos como os docentes significam e articulam os apoios pedagógicos, as redes de subjetivação que professores estabelecem de si e dos alunos mediante a deficiência, dentre outras questões, tendo como horizonte a sala de aula comum - espaço tempo privilegiado para o trabalho com o currículo comum que dará sustentação às ações do atendimento educacional especializado.

Há de se pensar que a mesma especificidade que leva esse indivíduo ao atendimento educacional especializado, também aparece na sala de aula comum, pois não escolarizamos um sujeito multifacetado que, em um determinado ambiente, apresenta certa necessidade enquanto essa mesma demanda se apaga em outro. Assim, temos nos desafiado a pensar o impacto dessa especificidade no coletivo da sala de aula comum, não alçando esse ambiente ao lugar de coadjuvante em detrimento dos espaços especializados, mas buscando diálogos para que tanto um espaço quanto o outro protagonizem ações pedagógicas para sustentar os processos de desenvolvimento desses estudantes (VIEIRA, 2012, p. 30).

Um estudo realizado em âmbito nacional denominado Observatório Nacional de Educação Especial: estudo em rede nacional sobre as salas de recursos multifuncionais nas escolas comuns (MENDES, 2010), também em abrangência no Estado do Espírito Santo, apontou pistas que são significativas para pensarmos na relação entre currículo e Educação Especial. Uma primeira delas é a necessidade de ajudarmos as escolas a romperem com a lógica da socialização (simplificada na convivência entre pares) em detrimento do acesso ao conhecimento. Há ainda a necessidade de atribuição de um sentido plural ao atendimento educacional especializado para ele não se resumir às ações pedagógicas de contraturno realizado em salas de recursos multifuncionais.

Além disso, a inclusão de alunos com deficiência, transtornos globais do desenvolvimento e altas habilidades, superdotação - embora consubstanciada como um direito público e subjetivo em vários documentos normativos - em vários cenários escolares é ainda subjetivada por "pontos de vista" ou como uma "possibilidade" que o docente tem de escolha: de envolver ou não o estudante nas ações planejadas e desenvolvidas no coletivo da sala de aula comum. Dependendo da escolha, muitas vezes, a sala de recursos multifuncionais é alocada como espaço de acolhimento dos que desafiam a sala de aula comum. Os laudos parecem ainda se colocar como balizadores do processo de ensino-aprendizagem e um conjunto de mitos sobre a pessoa com deficiência (que há uma legislação que garante promoção automática, por exemplo) busca produzir determinismos que ganham tons de verdades absolutas.

Não obstante a esse cenário, os processos de ensino-aprendizagem e de avaliação, muitas vezes, dão centralidade à deficiência, promovendo o apagamento do sujeito, fazendo a escola compor práticas pedagógicas e atividades simplórias que pouco contribuem com a formação de um sujeito que se constitui humano por meio do acesso às culturas, na relação com o outro, no desenvolvimento na linguagem e por meio do mundo simbólico, como diria Vygotsky (1998). Ganham destaque as atividades de recorte e colagem, os jogos, as atividades nos computadores, os quebra-cabeças ou até mesmo a elaboração de cadernos com um conjunto de atividades xerografadas desconexas que são afixadas representando o que pode ser chamado de currículo para o aluno com indicativos à Educação Especial.

Diante disso, é preciso intensificar as ações de colaboração (já realizadas em alguns cenários educacionais) entre pedagogos, professores do núcleo comum e docentes do atendimento educacional especializado para se pensar em estratégias para acessibilidade a um currículo comprometido com o desenvolvimento integral do sujeito, tendo em vista esse processo de troca se constituir em uma possibilidade de formação para todos os sujeitos envolvidos que se corresponsabilizam pelo estudante.

Há de se pensar em políticas de formação de professores - inicial e continuada - de modo que teoria e prática possam apontar caminhos profícuos para pensarmos em currículos abertos e acessíveis que fazem dialogar as comunalidades que atravessam os direitos de aprendizagem de todo cidadão brasileiro, mas também as especificidades de grupos sociais de estudantes (como os com deficiência, por exemplo), mas sem produzir um processo de canibalização de conhecimentos, como diria Boaventura de Sousa Santos (2008), mas, ao contrário, um processo de tradução. Por isso, a relevância dos investimentos na formação dos professores, pois de acordo com Meirieu (2002), o professor não pode ser um prático puro e muito menos um teórico puro, pois a inventividade pedagógica se dá quando o professor se assume como sujeito de conhecimento (aquele que se alimenta das teorias da Educação e as produz) e planeja 
e medeia práticas pedagógicas capazes de atender às diferentes trajetórias dos alunos.

Pensando nos processos de formação docente, concordamos com Duarte (2006), ao considerar que a historicidade do ser humano é gerada pelo trabalho, e isso é o que diferencia a realidade social da realidade puramente biológica e natural. O homem, antes de qualquer coisa, é um ser vivo, isto é, um ser cuja existência jamais pode transcorrer sem a base biológica. Mas, a interlocução entre essa base biológica com a mediação, a linguagem e o acesso à cultura é que faz com que o homem desenvolva as funções psicológicas superiores.

Aqui, cabe-nos questionar: a formação inicial e continuada tem pensado os processos de formação considerando que nossos professores estão produzindo cultura mediante o trabalho? A ausência de uma política de formação inicial e continuada - que articula a compreensão sobre o que é trabalho, trabalho docente e o fortalecimento da formação docente - fragiliza a elaboração de propostas pedagógicas que consideram os estudantes como sujeitos de direito? E ainda, como a formação deve articular a formação geral e específica, uma vez que no campo da Educação Especial temos fomentado, nos últimos anos, mais formações específicas da área do que formações mais amplas articuladas com o cotidiano da sala de aula.

É preciso, portanto, pensar na formação do educador como um processo que devolve ao homem/mulher sua história como trabalhador(a) que junto com "outros sujeitos" altera intencionalmente as condições exteriores, modificando-se a si mesmo. "A escola só será inclusiva quando souber lidar com a diversidade na unidade; quando souber trabalhar pedagogicamente com diferenças e não tentando homogeneizá-las" (ROCHA, 2002, p. 68).

Esse processo remonta a constituição do professor crítico-reflexivo que assume a pesquisa como eixo de sua formação e que se alia à ideia da concepção do trabalho docente de forma colaborativa (VICTOR, 2012). Finalizamos essas análises refletindo sobre a necessidade de investimentos na formação de professores especializados, mas também dos docentes do núcleo comum, para rompermos, assim, com um ciclo muito vicioso em muitos sistemas de ensino: a pouca circulação dos conhecimentos produzidos no campo da Educação Especial entre os demais profissionais da Educação. Há de se pensar em estratégias formativas para que os professores tenham condições de estudar, de aprofundar teoricamente os seus conhecimentos e de produzir novas teorias a partir do vivido nas escolas, afastando as perspectivas formativas que mais se aproximam de momentos coletivos que trazem informações superficiais para os docentes, que pouco contribuem com a constituição de novas práticas.

\section{Considerações Finais}

No Brasil, avolumam-se os debates e as teorizações em torno dos currículos escolares, principalmente em tempos de existência de uma Base Nacional Comum Curricular. Crescem preocupações quanto ao documento quando ideologias, relações de poder e culturas hegemônicas trazem implicações sobre o que será levado enquanto conhecimento a ser ensinado nas escolas, ditando certo modelo de sociedade que nega o pluralismo de ideias e modos de manifestação da vida humana. Há receios quanto à composição de currículos mínimos e únicos (em detrimento da riqueza cultural brasileira), pensados para padrões de alunos para atender agências multinacionais em nome da Educação com qualidade. Existem preocupações acerca da constituição de currículos para favorecer avaliações de larga escala, desmerecendo a formação integral do estudante - função social da escola.

No campo da Educação Especial, currículos não acessíveis e conteudistas, reforçam os pressupostos da adequação/flexibilização/adaptação curricular, muitas vezes, assumidas como empobrecimento do que é ensinado aos alunos, principalmente quando o foco das intervenções são as deficiências dos sujeitos e não os seus processos de constituição históricos e sociais. Diante disso, há de se apostar em documentos orientadores curriculares que fazem transversalizar a Educação Especial em toda a sua composição para se pensar em como garantir o acesso ao conhecimento comum e às especificidades que atravessam a formação de sujeitos que trazem condições peculiares de aprendizagem para a escola comum que demandam do apoio do atendimento educacional especializado.

\section{REFERÊNCIAS}

ALVES, Nilda. Sobre a possibilidade e a necessidade curricular de uma base nacional comum. Revista e-Curriculum, São Paulo, v. 12, n. 3, p. 1464-1479, out./dez. 2014.

APPLE, Michael W. Ideologia e currículo. 3. ed. Tradução de Vinícius Figueira. Porto Alegre: Artmed, 2006.

ARROYO, Miguel G. Currículo, território em disputa. Petrópolis: Vozes, 2013.

ARROYO, Miguel G. Ofício de mestre: imagens e auto-imagens. Petrópolis: Vozes, 2000.

ASSOCIAÇÃO NACIONAL DE PÓS-GRADUAÇÃO E PESQUISA EM EDUCAÇÃO. Ofício no 01/2015/

GR. Exposição de motivos sobre a base nacional comum curricular. Rio de Janeiro: ANPED, 2015. https://doi. org/10.9771/peri.v1i2.12886 
BAPTISTA, Claudio Roberto. Ação pedagógica e educação especial: a sala de recursos como prioridade na oferta de serviços especializados. Revista Brasileira de Educação Especial, Marília, v. 17, n. spe. 1, p. 59-76, maio/ago. 2011. https://doi.org/10.1590/s1413-65382011000400006

BARBIER, René. A pesquisa-ação. Tradução de Lucie Didio. Brasília: Líber Livro, 2004.

BRASIL. Ministério da Educação. Política pública de educação especial na perspectiva da educação inclusiva. Brasília: MEC, 2008. Disponível em: http://portal.mec.gov. br/arquivos/pdf/politicaeducespecial.pdf. Acesso em: 10 mar. 2009. https://doi.org/10.17648/galoa-cbee-6-29723

BRASIL. Lei no 9.394, de 20 de dezembro de 1996. Estabelece as diretrizes e bases da educação nacional. Diário Oficial [da] República Federativa do Brasil: seção 1, Brasília, DF, 23 dez. 1996. https://doi.org/10.11117/ 22361766.56.11.2374

BRASIL. [Constituição (1988)]. Constituição da República Federativa do Brasil. Brasília: Senado Federal, 1988. https://doi.org/10.11606/d.2.2010.tde-13122010-160747

BRASIL. Lei no 8.069, de 13 de julho de 1990. Dispõe sobre o Estatuto da Criança e do Adolescente e dá outras providências. Diário Oficial da União, Brasília, DF, 16 jul. 1990. https://doi.org/10.1590/0034-716719730005000016

BRASIL. Lei no 13.005 , de 25 de junho de 2014. Aprova o Plano Nacional de Educação - PNE e dá outras providências. Diário Oficial da União, Brasília, DF, 25. jun. 2014. https://doi.org/10.22420/rde.v11i20.774

CARVALHO, Janete Magalhães. A razão e os afetos na potencialização de "bons encontros" no currículo escolar: experiências cotidianas. In: FERRAÇO, Carlos Eduardo (org.). Currículo e educação básica: por entre redes de conhecimento, imagens, narrativas, experiências e devires. Rio de Janeiro: Rovelle, 2011. v. 1, p. 103-121. https://doi. org/10.15603/978-85-7814-334-3.1

CORREIA, Gilvane Belem. Deficiência, conhecimento e aprendizagem: uma análise relativa à produção acadêmica sobre educação especial e currículo. 2016. Dissertação (Mestrado em Educação) - Programa de Pós-Graduação em Educação, Faculdade de Educação, Universidade Federal do Rio Grande do Sul, Porto Alegre, 2016. https://doi. org/10.30553/sociologiaonline.2017.15.2

CURY, Caros Roberto Jamil. A educação básica no Brasil. Educação \& Sociedade, Campinas, v. 23, n. 80, p. 168-200, set. 2002. https://doi.org/10.1590/s0101-73302002008000010

DUARTE, Adriana Maria Cancella. O processo de trabalho docente na educação básica: a análise dos pesquisadores da Rede Estrado. Revista de Ciências Humanas, v. 6, n. 2, p. 239-252, jul./dez. 2006.

FERRAÇO, Carlos Eduardo. Currículo e imagem e narrativa e rede e experiência e diferença e/ou sobre conversas, encontros e devires. In: FERRAÇO, Carlos Eduardo (org.). Currículo e educação básica: por entre redes de conhecimento, imagens, narrativas, experiências e devires. Rio de Janeiro: Rovelle, 2011. v. 1, p. 11-50. https://doi.org/10.12957/ riae. 2016.24882

GARCIA, Rosalba Maria Cardoso. O conceito de flexibilidade curricular nas políticas públicas de inclusão educacional. In: JESUS, Denise Meirelles et al. (org.). Inclusão, práticas pedagógicas e trajetórias de pesquisa. Porto Alegre: Mediação, 2007. https://doi.org/10.11606/t.48.2009.tde24092009-161637

GIMENO SACRISTÁN, J. G. A construção do discurso sobre a diversidade e suas práticas. In: ALCUDIA, Rosa et al. Atenção à diversidade. Porto Alegre: Artmed, 2002. p. 161184.

GIMENO SACRISTÁN, J. O currículo: uma reflexão sobre a prática. 3. ed. Tradução de Ernani F. da F. Rosa. Porto Alegre: Artmed, 2000.

GIROUX, Henry. Teoria crítica e resistência em educação: para além das teorias da reprodução. Petrópolis: Vozes, 1986.

HAAS, Clarissa; BAPTISTA, Claudio Roberto. Currículo e educação especial: uma relação de (re) invenção necessária a partir das imagens-narrativas dos cotidianos escolares. In: REUNIÃO NACIONAL DA ANPED, 37., 2015, Florianópolis. Anais [...]. Florianópolis: UFSC, 2015. Disponível em: http://37reuniao.anped.org.br/wp-content/ uploads/2015/02/Trabalho-GT15-4199.pdf. Acesso em: 24 jan. 2016. https://doi.org/10.17648/galoa-cbee-6-28655

MACEDO, Elizabeth. Base Nacional Curricular Comum: novas formas de sociabilidade produzindo sentidos para educação. Revista e-Curriculum, São Paulo, v. 12, n. 3, p. 1530-1555, out./dez. 2014.

MEIRIEU, Philippe. A pedagogia entre o dizer e o fazer: a coragem de recomeçar. Tradução de Fátima Murad. Porto Alegre: Artmed, 2002.

MEIRIEU, Philippe. La escuela, modo de empleo: de los 'métodos activos' a la pedagogía diferenciada. Barcelona: Ediciones Octaedros, 1997.

MENDES, Enicéia Gonçalves. O que fazem os educadores de creches com suas crianças com necessidades educacionais especiais. In: Encontro Nacional de Didática e Prática de Ensino, 13., 2006, Recife. Trabalho [...]. Recife: [s.n.], 2006. https://doi.org/10.11606/t.47.2018.tde-05022018-155845

MENDES, E. G. Observatório Nacional de Educação Especial: estudo em rede nacional sobre as salas de recursos multifuncionais nas escolas comuns. Brasília: [s.n.], 2010. https://doi.org/10.17648/galoa-cbee-6-28574

MOREIRA, Antônio Flávio; TADEU, Tomaz. Sociologia e teoria crítica do currículo: uma introdução. In: MOREIRA, Antônio Flávio; TADEU, Tomaz (org.). Currículo, cultura e sociedade. 10. ed. São Paulo: Cortez, 2008. p. 7-37. 
PIETRO, Rosangela Gavioli. Educação Especial em municípios paulistas: histórias singulares ou tendência unificadora. In: BAPTISTA, Claudio Roberto; JESUS, Denise Meyrelles de. (Org.). Avanços em políticas de inclusão: o contexto da educação especial no Brasil e em outros países. Porto Alegre: Mediação, 2009. https://doi.org/10.11602/19844271.2018.11.3.4

ROCHA, Rosanes. Educação especial: onde está a diferença? In: SOUZA, Regina Célia de; BORGES, Maria Fernanda S. Tognozzi (org.). A práxis na formação de educadores infantis. Rio de Janeiro: DP\&A, 2002. p. 61-71.

SANTOS, Boaventura de Sousa. A gramática do tempo: para uma nova cultura política. 3. ed. São Paulo: Cortez, 2006.

https://doi.org/10.1590/s0102-64452008000100002

SANTOS, Boaventura de Sousa. A filosofia à venda, a douta ignorância e a aposta de Pascal. Revista Crítica de Ciências Sociais, Coimbra, n. 80, p. 11-43, mar. 2008. https://doi.org/ 10.4000/rces.691

VIEIRA, Alexandro Braga. Táticas e estratégias constituídas por professores para a articulação do currículo escolar e o atendimento educacional especializado. 2015. Relatório (Pós-Doutorado em Educação) - Programa de Pós-Graduação em Educação, Universidade Federal do Espírito Santo, Vitória, 2015. https://doi. org/10.29280/rappge.v2i2.4342

VICTOR, Sonia Lopes. As produções acadêmicas em educação especial na educação infantil: análise da formação de professores. Revista de Ciências Humanas, Frederico Westphalen, v. 13, n. 21, p. 79-97, dez. 2011. https://doi. org/10.5151/9788580392258-01

VYGOTSKY, Lev Semenovitch. A formação social da mente. São Paulo: Martins Fontes, 1998.

Recebido em: 1/6/2017.

Aprovado em: 21/11/2018.

Publicado em: 8/11/2019.

Endereço para correspondência:

Alexandro Braga Vieira

Universidade Federal do Espírito Santo - Centro de Educação

Programa de Pós-Graduação de Mestrado Profissional em Educação

Av. Fernando Ferrari, 514

29075-910,Vitória, ES, Brasil

\section{Autores:}

Alexandro Braga Vieira

Doutor em Educação pela Universidade Federal do Espírito Santo.

Universidade Federal do Espírito Santo (UFES), Vitória, Brasil.

Orcid: http://orcid.org/0000-0001-5952-0738

E-mail: allexbraga@hotmail.com

Sumika Soares de Freitas Hernandez-Piloto

Doutora em Educação pela Universidade Federal do Espírito Santo.

Secretaria Municipal de Educação de Vitória, ES, Brasil.

Orcid: http://orcid.or/0000-0002-0235-8757

E-mail: sumika.freitas@gmail.com

INES DE Oliveira Ramos

Doutora em Educação pela Universidade Federal do Espírito Santo.

Universidade Federal do Espírito Santo (UFES), Vitória, ES, Brasil.

Orcid: http://orcid.org/0000-0003-2019-8600

E-mail: inesram.ufes@gmail.com 